march_2016.pdf (accessed 10 Nov 2020).

6. Allsop MJ, Kite S, McDermott S, et al. Electronic palliative care coordination systems: devising and testing a methodology for evaluating documentation. Palliat Med 2017; 31(5): 475-482.

DOI: https://doi.org/10.3399/bjgp20X713633

\section{Multidisciplinary teams must work together to co-develop inclusive digital primary care for older people}

The COVID-19 pandemic has abruptly changed healthcare service delivery. ${ }^{\text {I In }}$ a few weeks, clinicians and patients were asked to transition from face-to-face contacts to 'digital-first' solutions (that is, telephone, video, online) wherever possible.

However, there is a real risk that innovation entrenches inequalities in care access, delivery, and patient safety. ${ }^{2}$ The adoption of digital technologies is known to happen unevenly across different groups, therefore contributing to the so-called 'digital divide. ${ }^{3}$ Older people seem to be particularly underserved: evidence shows that increased age is associated with less access to technology and lower digital literacy, ${ }^{3,4}$ which may contribute to lower adoption, less sustained use, and less access to care and treatment. Paradoxically, this same group was identified as high risk and is more likely to have comorbidities, physical disabilities, and be shielding, ${ }^{5}$ and, therefore, they have most to gain from the regular and remote care that digital technologies can offer.

For these reasons, it is critical to work with a diverse group of older people, particularly from seldom heard groups. GPs and other healthcare providers, researchers, designers, and relevant voluntary and community organisations must come together to explore the main barriers and enhancers to access remote and digital care, and find innovative ways to translate these findings into high-quality solutions to improve the experience both for providers and patients - in order to deliver high-quality, patient-centred care that leaves no one behind.

Ana Luisa Neves,

Research Fellow in Clinical Analytics and
Patient Safety, Institute of Global Health Innovation, Imperial College London, London. Email: ana.luisa.neves14@imperial.ac.uk

Anna Lawrence-Jones,

Patient and Public Involvement and Engagement Lead, Institute of Global Health Innovation, Imperial College London, London.

Lenny Naar,

Head of Design Strategy, Helix Centre, Institute of Global Health Innovation, Imperial College London, London.

\section{Geva Greenfield,}

Research Fellow in Public Health, Department of Primary Care and Public Health, School of Public Health, Imperial College London, London.

Frances Sanderson,

Consultant in Infectious Disease, Imperial College Healthcare NHS Trust, London.

Toby Hyde,

Deputy Director of Transformation, Imperial College Healthcare NHS Trust, London.

\section{David Wingfield}

GP and Honorary Senior Lecturer, Hammersmith and Fulham Partnership, London.

lain Cassidy,

CEO, Open Age, London.

Erik Mayer,

Institute of Global Health Innovation, Imperial College London, London.

\section{REFERENCES}

1. Blumenthal D, Fowler EJ, Abrams M, Collins SR Covid-19 - implications for the health care system. N Engl J Med 2020; 383(15): 1483-1488. DOI: 10.1056/NEJMsb2021088. Epub 2020 Jul 22. Erratum in: N Engl J Med 2020 Jul 23; PMID: 32706956.

2. Crawford $A$, Serhal E. Digital health equity and COVID-19: the innovation curve cannot reinforce the social gradient of health. J Med Internet Res 2020; 22(6): e19361. Published 2020 Jun 2. DOI: $10.2196 / 19361$.

3. Watts G. COVID-19 and the digital divide in the UK Lancet Digit Health 2020; 2(8): e395-e396. DOI: 10.1016/S2589-7500(20)30169-2.

4. Sørensen K, Van den Broucke S, Fullam J, et al.
Health literacy and public health: a systematic review and integration of definitions and models. BMC Public Health 2012; 12(1): 80. DOI: 10.1186/1471-2458-12-80.

5. Dhama K, Patel SK, Kumar R, et al. Geriatric population during the COVID-19 pandemic: problems, considerations, exigencies, and beyond. Front Public Health 2020: 8: 574198 . DOl: 10.3389/ fpubh.2020.574198. PMID: 33072713; PMCID: PMC7536316.

\section{Competing interests}

Ana Luisa Neves, Anna LawrenceJones, and Erik Mayer are supported by the Imperial National Institute for Health Research (NIHR) Patient Safety Translational Research Centre, with infrastructure support from the NIHR Biomedical Research Centre. Geva Greenfield is supported by the NIHR Applied Research Collaboration Northwest London. The views expressed in this publication are those of the authors and not necessarily those of the National Institute for Health Research or the Department of Health and Social Care.

DOI: https://doi.org/10.3399/bjgp20X713645

\section{Herd thinking}

Thank you for your remarks on COVID vaccination in your October editorial "Herd thinking.' ' You are absolutely right that the positivist philosophical approach that some doctors might use to persuade patients of the benefits of vaccination is often not shared by the patients.

However, all is not lost. As I described in an article in your journal, ${ }^{2}$ the way forward is to identify the patient's explanatory perspective and, having identified it, to respond within that perspective. This is a technique that every successful salesman has learnt and which I make no claim to have invented. In the case of immunisation, many of the papers quoted in that article come from the World Health Organization 'Sociology and Immunisation Project', which has sponsored relevant research all over the world.

Much has been written and well written about immunisation since, ${ }^{3}$ but I do not think that this basic point has been superseded.

Gervase Vernon,

Retired GP, John Tasker House Surgery,

Dunmow, Essex.

Email: gvernonanhs.net 